UNIVERSIDADE DE SÃO PAULO

FACULDADE DE ADMINISTRAÇÃO, ECONOMIA E CONTABILIDADE DEPARTAMENTO DE ECONOMIA

PROGRAMA DE PÓS-GRADUAÇÃO EM ECONOMIA

Jurisprudência, Comprometimento e o Mercado de Empréstimos

Guilherme Froldi Carrozza

Orientador: Prof. Dr. Gabriel de Abreu Madeira

Outubro 2012

São Paulo 
Prof. Dr. João Grandino Rodas

Reitor da Universidade de São Paulo

Prof. Dr. Reinaldo Guerreiro

Diretor da Faculdade de Economia, Administração e Contabilidade

Prof. ${ }^{a}$ Dra. Elizabeth Maria Mercier Querido Farina

Chefe do Departamento de Economia

Prof. Dr. Pedro Garcia Duarte

Coordenador do Programa de Pós-Graduação em Economia 
Guilherme Froldi Carrozza

\section{Jurisprudência, Comprometimento e o Mercado de Empréstimos}

Dissertação apresentada ao Departamento de Economia da Faculdade de Economia, Administração e Contabilidade da Universidade de São Paulo como requisito para a obtenção do título de Mestre em Ciências.

Orientador: Prof. Dr. Gabriel de Abreu Madeira

Outubro 2012

Versão Corrigida

(versão original disponível na Unidade que aloja o Programa)

São Paulo 
FICHA CATALOGRÁFICA

Elaborada pela Seção de Processamento Técnico SBD/FEA-USP

Carrozza, Guilherme Froldi

Jurisprudência, Comprometimento e o Mercado de Empréstimos / Guilherme Froldi Carrozza - São Paulo, 2012.

$64 \mathrm{p}$.

Dissertação (Mestrado) - Universidade de São Paulo, 2011

Orientador: Gabriel de Abreu Madeira.

1. Crédito 2. Sistema Financeiro 3. Direito

I. Universidade de São Paulo. Faculdade de Economia, Administração

e Contabilidade. II. Título.

CDD - 332.7 
Aos meus entes queridos 


\section{AGRADECIMENTOS}

Agradeço, em primeiro lugar, aos meus pais, Vanda e Domingos, pelo apoio incondicional que recebi durante minha vida e minha trajetória acadêmica. Esta dissertação sem dúvidas, é muito mais deles do que minha propriamente. Reconheço também o apoio, igualmente importante, do meu irmão Danilo.

Não poderia deixar de agradecer especialmente a Paula, que sem dúvida desempenhou um papel fundamental para a conlusão deste trabalho.

Cabe também agradacer aos amigos que me acompanharam desde a gradução : Marcel, Rafael, Henrique, Alexandre, Leandro, Seiji, Marcelo e João. Sem dúvida a jornada foi mais engraçada, tranquila e produtiva na presença deles. Fica também meu agradecimento aos amigos da FEA: André, Eduardo, Alexandre, Victor, Paraíba, João, Gato e Paulo. Embora nossa relação não tenha sido tão intensa eles sempre estiveram presentes nos momentos em que precisei de algum suporte. Cabe um agradecimento especial ao meu orientador, Prof. Dr. Gabriel De Abreu Madeira pelas excelentes críticas recebidas ao longo do desenvolvimento do trabalho, e por todo o apoio, atenção e respaldo que recebi.

Por último, agradeço à $\mathrm{CNPq}$, pelo apoio financeiro. 
"Banco é onde nos emprestam guarda-chuvas quando faz sol e pedem de volta quando ameaça chover". Robert Frost 


\section{RESUMO}

A literatura empírica tem dado atenção crescente à idéia de que a origem legal de um país explica diferenças de desenvolvimento financeiro entre íses. Resultados empíricos sugerem que países que têm suas leis comerciais e cooperativas baseadas na tradição legal britânica, lei comum, teriam mercados de capitais e financeiro em geral mais desenvolvidos do que países que têm suas leis ancoradas na tradição legal francesa, ou seja, lei civil. Uma diferença clara entre as duas tradições seria o peso da jurisprudência, ou seja, o quanto decisões passadas servem de base para as decisões presentes. Essencialmente, a tradição britânica se caracteriza por dar grande, ou total, peso para a jurisprudência no julgamento de um caso. Já a tradição civil tem como característica tomar uma decisão com base em um código e não na jurisprudência. Dada esta diferença vamos propor um modelo em que a jurisprudência desempenha papel fundamental para aumentar o nível de empréstimo disponível. Como vamos obervar neste estudo, na presença de jurisprudência o juiz leva em conta o efeito que sua decisão tem sobre o futuro, o que estimula um maior grau de proteção para credores, contribuindo para o desenvolvimento do mercado de empréstimos. Quanto maior o custo de o juiz tomar uma decisão diferente da que foi tomada no passado, maior será o volume de crédito da economia e a taxa de juros de equilíbrio. Adicionalmente, quanto maior a ênfase dada ao componente de jurisprudência em detrimento do peso dado à uma dada recomendação legal, maior o volume de crédito. 


\begin{abstract}
The empirical literature has given increasing attention to the idea that the country's legal origin explains differences in financial development. Empirical results suggests that countries with comercial and cooperative laws based in the common law tradition, would have financial and capital markets generally more developed than countries that have their laws anchored in the civil law. The main difference between the two traditions is the role of jurisprudence, in other words, as past decisions form the basis to present decisions. Essentially, the British tradition is characterized by emphasize the jurisprudence in a trial. On the other hand, a civil tradition is characterized by a decision based on a code. We propose a model where jurisprudence plays a key role in increasing the amount of loan available. The results suggests that considering jurisprudence the judge takes into account the effect that his decision has on future decisions, which implies in a greater degree of protection for lenders, contributing to the market loans development. The higher the cost for the judge to take a different decision from that taken in the past, greater the amount of credit in the economy and the equilibrium interest rate. Additionally, greater emphasis on the jurisprudence instead of a code, the greater is the volume of credit.
\end{abstract}




\section{Sumário}

$\begin{array}{ll}\text { Lista de Figuras } & \text { XV }\end{array}$

1. Introdução . . . . . . . . . . . . . . . . . . . . 5 5

1..1 Evidência Empírica e Estudos Relacionados . . . . . . . . . . . 7

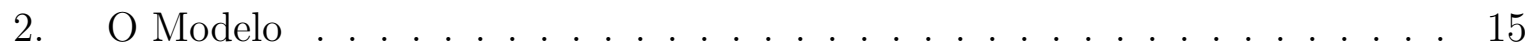

2.1 Escolha Ótima dos Agentes Irrestritos . . . . . . . . . . . . 16

2..2 Escolha Ótima dos Agentes Restritos . . . . . . . . . . . . 18

$2 . .3 \quad$ O Agente Judiciário . . . . . . . . . . . . . . . . . . . . . . . 19

2..4 A Tomada de Decisão do Judiciário: O Efeito da Jurisprudência 21

2..5 Juros e Empréstimos de Equilíbrio. . . . . . . . . . . . . . . 26

2..6 Resolvendo o Modelo . . . . . . . . . . . . . . . . . . . 29

$2.7 \quad$ Jurisprudência e o Volume de Crédito . . . . . . . . . . . . . . . . . 31

$2 . .8 \quad$ Jurisprudência e a Taxa de Juros . . . . . . . . . . . . . . . . . . . 33

2.9 Resultados Numéricos . . . . . . . . . . . . . . . . 34

3. Ênfase do Sistema Legal: Jurisprudência e Recomendação Legal . . . . . . 37

3..1 Resultados Numéricos . . . . . . . . . . . . . . . . 37

4. Considerações Finais . . . . . . . . . . . . . . . . . . . 41

5. Referências Bibliográficas . . . . . . . . . . . . . . . 43 


\section{Lista de Figuras}

1 Cronologia dos eventos . . . . . . . . . . . . . . . 16

2 Situação irrestrita . . . . . . . . . . . . . . . . . . . . . . . 28

3 Situação restrita . . . . . . . . . . . . . . . . . . . . . . 28

4 Montante de empréstimos de equilíbrio como função do custo da jurisprudência . . . . . . . . . . . . . . . . . . 35

5 Taxa de juros de equilíbrio como função do custo da jurisprudência . . . . 35

6 Excedente social esperado como função do custo da jurisprudência . . . . . 36

7 Taxa de juros de equilíbrio como função de $\gamma \ldots$. . . . . . . . . . . . . 38

8 Empréstimos de equilíbri como função de $\gamma \ldots \ldots$. . . . . . . . . . . 38

9 Volume de crédito como função do custo da jurisprudência e de $\gamma$. . . . . 39

10 Empréstimos de Equilíbrio como função do custo da jurisprudência e de $\gamma$. 39

11 Juros de Equilíbrio como função do custo da jurisprudência e de $\gamma$. . . . . 39 


\section{Introdução}

A lei comum é geralmente ausente de códigos, ou seja, as leis e estatutos não são compilados e formalizados. Desta forma, sob a tradição da lei comum, uma decisão judicial é tomada com base em precedentes, ou seja, decisões judiciais anteriores que foram tomadas em casos similares. Estes precedentes são arquivados pelos júris em livros anuais e relatórios. Vale ressaltar que os precedentes que devem ser aplicados para o julgamento de um novo caso são definidos por um júri, fazendo com que estes tenham um papel fundamental em modificar a lei. Um julgamento sob a tradição britânica consiste em duas partes contrárias. Com base nisso um júri formado por pessoas comuns, sem treinamento ou conhecimento legal específico, decide com base nos fatos. Na sequência um juiz determina uma sentença apropriada levando em conta a decisão do júri, o veredito.

Por outro lado, sob o regime da lei civil as decisões são tomadas com base em um código abrangente, que deve ser frequentemente atualizado. Este código deve definir as situações e assuntos habilitados a serem levados para o tribunal, o procedimento que deve ser aplicado e a punição que deve ser aplicada para cada situação. Sendo assim em um sistema de lei civil o papel do juiz é estabelecer os fatos e aplicar uma regra pré-determinada. Desta forma os juízes tem pouco papel em mudar e atualizar as leis.

Recentemente a literatura empírica e teórica tem voltado sua atenção para as implicações econômicas de diferentes sistemas legais. Esta questão ganhou destaque após La Porta, Lopez-de-Silanes, Shleifer e Vishny terem publicado uma série de artigos classificando os sistemas legais dos países de acordo com a tradição legal que serviu como base para seus códigos; Lei Comum ou Lei Civil. Como veremos neste estudo um país que tem seu sistema legal baseado na lei comum apresentaria um maior volume de crédito na economia em função da ênfase que esta tradição dá para a jurisprudência. Após estes artigos, um número significativo de estudos empíricos foi feito. Muitos artigos encontram uma correlação positiva entre origem legal baseada na tradição da commom law, tradição britânica, e mercados financeiros mais desenvolvidos. O que difere substancialmente as duas tradições, 
seria o papel da jurisprudência. Em países de lei comum a jurisprudência esta sempre presente e forma a base de um julgamento. Na lei civil por sua vez a jurisprudência nem sempre é levada em conta, e quando é o caso ela exerce um papel complementar.

Este artigo pretende investigar a relação entre jurisprudência e comprometimento judicial, na medida em que quanto maior o peso da jurisprudência maior o comprometimento do juiz com decisões passadas e futuras. Será proposto um modelo teórico onde a jurisprudência desempenha um papel fundamental para fornecer uma explicação do por que países de lei comum teriam um maior desenvolvimento financeiro. Ao resolver o modelo conclui-se que a partir de uma dado volume de crédito, tudo o mais constante, o juiz opta por determinar que os empréstimos não sejam pagos. No entanto, como veremos, o calote nunca será uma decisão que configura um equilíbrio uma vez que os agentes antecipam esta decisão ao escolher o montante de empréstimos que escolherão. Outro resultado é que por serem os emprestadores quem estão restritos, um relaxamento da restrição implica em um maior volume de crédito ofertado e uma maior taxa de juros. Por fim o resultado principal é que observamos que quanto maior o peso dado à jurisprudência em detrimento do peso dado à uma recomendação legal, maior o volume de crédito de equilíbrio.

Na seção 2 apresentaremos o modelo que serve como base para o estudo. Nesta seção será definido o ambiente ecônomico , os personagens do modelo e como eles tomam suas decisões. Na seção 3 resolveremos numericamente o modelo geral tal como proposto em 2. Por fim na seção 4 apresentaremos uma breve conclusão. 


\section{1..1 Evidência Empírica e Estudos Relacionados}

No primeiro artigo de uma série, Porta et al. (1997) conjecturam que a natureza e eficiência dos sistemas financeiros ao redor do mundo podem ser explicadas, em parte, pela diferença de proteção legal recebida por investidores. Estas proteções seriam as leis existentes em um dado país, bem como a qualidade do comprometimento com estas, ou seja, o enforcement. Porta et al. (1997) encontram que estas leis e a qualidade do comprometimento variam significativamente de país para país. Os autores sugerem que a origem legal de cada país explicaria boa parte desta variação. O que Porta et al. (1997) fazem é classificar a origem legal de um país de acordo com quatro tradições jurídicas referentes às leis coorporativas e comerciais: Lei comum britânica, Lei civil francesa, Lei civil germânica e Lei civil escandinava. Utilizando dados de 49 países os autores concluem que países cujo sistema legal é oriundo da tradição britânica apresentam maior proteção aos acionistas e credores. Por outro lado os autores observam que países que adotaram a lei civil francesa são os que oferecem menor proteção. Outra conclusão interessante dos autores é que a qualidade do enforcement seria menor nos países que seguiram a tradição legal francesa.

Em um segundo artigo, os autores tentam mensurar a capacidade de firmas em diferentes ambientes legais, aumentar seu financiamento externo via dívida ou através da venda de parte de seu patrimônio. A ideia é que, supostamente, a disposição de um empresário em vender parte de seu patrimônio, ou assumir dívida, depende em grande parte dos termos sob os quais ele pode obter financiamento externo. Quando o canal é o da venda de parte do patrimônio, segundo os autores, esses termos estariam refletidos no valor presente dos fluxos de caixa, ou de forma geral, no processo de precificação. Quando estamos falando de dívida, os termos estariam refletidos no custo do financiamento. Segundo Porta et al. (1997) em países cujo sistema financeiro oferece melhores termos de financiamento externo, espera-se que exista um maior valor presente dos fluxos de caixa da empresa em questão 
e um mercado de capital mais desenvolvido, ou seja, onde mais firmas têm acesso ${ }^{1}$.

Com base nesta idéia e na premissa de que melhores proteções legais implicam em melhores termos aos empresários, os autores esperam que países com uma melhor proteção legal devam ter um maior financiamento externo através de um mercado de capital mais valorizado e desenvolvido. A fim de mensurar o tamanho do mercado financeiro de um país, os autores utilizam o número de firmas domésticas listadas neste mercado e o número de oferta pública de ações realizadas (IPO). Os autores comparam financiamento externo, em 49 países, como função da origem legal, qualidade da proteção legal dada aos investidores e qualidade do enforcement. O resultado que Porta et al. (1997) encontram é que em países cuja tradição legal segue a lei civil se observa um mercado de capital menos desenvolvido e uma frágil proteção aos investidores. Os autores ainda concluem que esse resultado é mais acentuado nos países que seguem a tradição legal francesa.

Posteriormente, em um terceiro artigo os autores buscam analisar empiricamente como as leis que protegem investidores e a qualidade com que estas leis são exercidas difere entre países. Com base nestas diferenças Porta et al. (1998) tentam explicar a variação que se observa na concentração de propriedade. Os autores começam identificando que as leis dos países não são tipicamente caseiras, ou seja, não são escritas por eles mesmos, normalmente essas leis são oriundas de alguma família legal. Porta et al. (1998) sugerem que as leis comerciais dos países são provenientes de basicamente duas tradições legais, a tradição britânica da lei comum e a tradição francesa da lei civil, baseada no direito romano. Desta maneira os autores realizam um estudo contendo dados de 49 países referentes aos direitos de investidores e à qualidade com que esses direitos são cumpridos e exercidos. Além destes dados, os autores utilizam dados referentes à concentração de propriedade. Seriam três as principais conclusões de Porta et al. (1998). A primeira é de que as leis relacionadas a investidores variam consideravelmente de país para país. Segundo Porta et al. (1998) países cuja origem legal se baseia na lei comum britânica tendem a proteger

\footnotetext{
${ }^{1}$ Para mais detalhes sobre o impacto da tradição legal sobre o processo de valoração e questões de governança ver Porta et al. (1999), Porta et al. (2000) e Vojislav (1998)
} 
melhor os investidores do que países cujo sistema legal seguiu a lei civil. Os autores ainda sugerem que esta diferença é maior ainda quando comparamos países de lei comum e lei civil francesa. Desta maneira os países que seguiram as leis civis escândinava e germânica se encontram em uma situação intermediária no que diz respeito à proteção que a lei oferece aos investidores. Sendo assim os direitos de um investidor ou acionista variam de acordo com o sistema legal que ele esta submetido. Mais precisamente variam de acordo com a origem deste sistema legal. Uma segunda conclusão dos autores é de que o enforcement legal, ou seja, o comprometimento com a execução destas leis, também varia consideravelmente entre os países. O resultado de Porta et al. (1998) sugere que países cujo sistema legal é oriundo da tradição civil germânica e escândinava oferecem um maior comprometimento com a execução e cumprimento destas leis, ou seja, estes países gozam de uma melhor qualidade no enforcement legal. No que diz respeito aos países de lei com origem na lei comum britânica temos que estes também gozam de uma qualidade bastante elevada no enforcement legal. No entanto, os países com sistema legal baseada na lei civil francesa são os que apresentam pior qualidade. Por fim temos que, ao analisarem os dados referentes à concentração de propriedade em companhias negociadas em bolsa, os autores não rejeitam a hipótese de que alta concentração de propriedade seria uma resposta à pouca proteção oferecida aos investidores.

Em linhas gerais La Porta, Lopez-de-Silanes, Shleifer e Vishny encontram evidência de que o fato de a lei comercial ou corporativa de um país estar baseada na tradição legal britânica, escandinava, germânica ou francesa seria importante para explicar a variação observada no desenvolvimento financeiro de um país. Sendo que este desenvolvimento financeiro seria mesurado através de variáveis como tamanho do setor bancário e capitalização no mercado de capitais. Posteriormente Zingales (2003) chamariam a atenção para o fato de que o desenvolvimento financeiro dos países não é algo monótono. Segundo os autores, a diferença no desenvolvimento financeiro entre os países muda com o passar do tempo. Desta forma Zingales (2003) argumentam que a origem legal de um país, por ser um fator constante, não serviria para explicar totalmente a diferença existente entre 
o desenvolvimento financeiro dos países. Zingales (2003) enaltecem a importância de fatores políticos para explicar parte desta diferença. Mesmo com esta suposta limitação da origem legal em explicar parte da diferença existente entre o desenvolvimento financeiro dos países, outros estudos empíricos foram feitos a fim de comprovar se realmente existe a relação entre origem legal e desenvolvimento financeiro. Beck et al. (2003c), expandem os estudos anteriores e utilizam uma medida diferente para desenvolvimento financeiro. Autores utilizam uma base de dados contendo mais de 100 países. A conclusão dos autores é que a origem legal de um país ajuda a explicar a diferença de desenvolvimento financeiro. Assim como os artigos anteriores, Beck et al. (2003c) encontram evidências de que países de lei civil francesa tendem a apresentar um mercado de capital menos desenvolvido. Os autores ainda encontram que países de lei civil francesa oferecem uma menor proteção aos direitos de propriedade privados. O trabalho dos autores ainda vale ser ressaltado pelo fato de terem feito uma tentativa inicial de controlar para diferenças nos sistemas políticos a fim de estabelecer uma relação mais precisa entre origem legal e desenvolvimento financeiro. Após controlar por fatores políticos os autores continuam encontrando que a origem legal de um país é significante para explicar diferenças no desenvolvimento do mercado de capitais, do setor bancário e do nível de proteção oferecida aos direitos de propriedades privados. Outra variável de controle incluída por Beck et al. (2003c) diz respeito a recursos naturais e fatores religiosos. E a conclusão inicial dos autores ainda é encontrada ${ }^{2}$. Com base nas evidências apontadas nos parágrafos anteriores fica claro que de fato há evidência na literatura ligando a origem legal de um país e desenvolvimento financeiro.

No que diz respeito à literatura teórica vale ressaltar o trabalho de Riboni (2006). Com a crescente atenção dada às implicações da origem legal de um país, o autor propõe um modelo teórico em que o foco é a decisão judicial sob a lei comum britânica e a lei civil. O modelo tem como base a hipótese de que o papel dos júris é garantir que a lei seja cumprida, ou seja, garantir o comprometimento das partes com a lei. O autor argumenta

\footnotetext{
${ }^{2}$ Para mais detalhes ver também Beck et al. (2003b) e Beck et al. (2003a)
} 
que as duas tradições legais implicam em diferentes modos de se resolver problemas de credibilidade e que esta diferença teria impacto na eficiência das decisões e da capacidade do sistema legal em questão, se adaptar às condições econômicas vigentes.

Segundo o autor, sob a lei comum britânica as leis são feitas pelo júri e a lei é estabelecida com base em decisões e precedentes judiciais. Desta forma ao tomar uma decisão, o tribunal deve levar em conta decisões anteriores. Sendo assim o tribunal de um sistema legal que tem como base a lei comum britânica resolveria um problema dinâmico. Já um sistema legal baseado na lei civil é um sistema codificado, onde o papel do júri é interpretar e aplicar o código, o que implicaria em um problema estático. O autor conclui que o precedente legal exerce um papel disciplinar na lei comum. A ideia é que o compromisso de que juízes conservadores aplicarão o precedente no futuro tende a sustentar uma situação que é ótima, mesmo que o juiz que venha a julgar goze de total independência. Além disso, o veredicto se torna mais previsível, reduzindo a incerteza. No que diz respeito à adaptabilidade dos sistemas legais os autores mostram que quando não existem problemas de credibilidade, os sistemas legais que têm como base a lei comum inovam a lei com mais cautela devido à existência do precedente. A ideia é que os tribunais são mais cautelosos em mudar o precedente quando se deparam com um choque, uma vez que no futuro outro choque pode fazer com que o novo precedente não seja justificável.

Outro trabalho que merece destaque é o de Gennaioli (2006). O foco do autor não é estabelecer uma comparação entres duas tradições legais e sim no processo de evolução da lei comum. O autor propõe um modelo em que o precedente evolui através de uma série de decisões dos jurados. O objetivo é entender como a lei comum evolui, quando esta evolução implica em melhoras para o sistema legal e se existe convergência das leis. O modelo proposto se apoia em três premissas básicas. A primeira é que os juízes estão sujeitos a algum viés em favor de diferentes tipos de réus. Além do mais, este viés é especifico de cada juiz. Sendo assim um juiz tem um viés que depende do réu e este viés varia de juiz para juiz. Segundo o autor existem evidências de que em alguns casos as decisões são tomadas levando-se em conta a posição ideológica dos juízes Outra hipótese 
feita é que o juiz tem um custo para mudar o precedente. A idéia é que para o juiz dar um parecer que vai contra o precedente ele deve se esforçar mais, investigando mais os fatos, argumentando mais e tendo maior exposição ao risco de receber críticas. Desta forma, adotar uma posição contrária ao precedente faz com que o juiz incorra em um custo adicional. Por fim o autor argumenta que a lei evolui quando os juízes distinguem um caso do precedente, ou seja, introduzem uma nova lei que endossa o precedente, e também adiciona uma nova dimensão que deve ser levada em conta, estabelecendo que a decisão judicial deva levar em conta o precedente, que agora se tornou lei, e esta nova dimensão. Desta forma o autor sugere que distinguir casos, tal como definido, seria o mecanismo central pelo qual a lei evolui. A conclusão é que as condições para aumentar a eficiência da lei comum são implausivelmente rigorosas. Além disso, uma lei que seja inicialmente ruim ou ineficiente tende a permanecer ineficiente mesmo sofrendo refinamentos. Isso por que as leis são altamente dependentes do passado. Apesar disso o autor argumenta que uma mudança legal, mesmo não tornando o sistema legal significativamente mais eficiente, tende a aumentar o bem estar social, uma vez que melhora a qualidade informacional do processo de decisão do judiciário, ao menos quando o custo de efetuar a mudança é baixo. Segundo Tetley (2000) a lei comum e a lei civil diferem, em sua essência, no papel que a jurisprudência exerce nos julgamentos. Na lei comum a jurisprudência exerce papel fundamental, criando um mecanismo de comprometimento, ou seja, como a decisão judicial é capaz de mudar a lei e abrir precedentes, o juiz pondera mais sua decisão. O que acontece é que o juiz leva em conta os efeitos que sua decisão pode ter sobre as decisões futuras. Na lei civil por outro lado este efeito não é tão evidente. Em alguns casos a jurisprudência é levada em conta na hora de uma decisão, mas apenas como fator complementar.

Neste estudo pretendemos analisar como o sistema legal afeta o mercado de crédito e como a existência de jurisprudência é capaz de aumentar o volume de crédito ofertado e o bem estar social. Desta forma este trabalho reside na intersecção entre imperfeições no mercado de crédito e sistema legal, ou seja, vamos analisar como diferentes sistemas legais afetam restrição de crédito e como esta restrição seria flexibilzada com o aumento do peso 
da jurisprudência. Na literatura referente ao mercado de crédito podemos citar o trabalho de Goldsmith (1969) como um dos pioneiros em apontar para a existência de uma relação entre a estrutura financeira de um país e o seu crescimento de longo-prazo, destacando que países menos desenvolvidos apresentam sistemas financeiros limitados. Quando o foco é imperfeições no mercado de crédito podemos considerar que estas começaram a ser estudadas com mais ênfase a partir do trabalho de Weiss (1981). Os autores apresentam um modelo que reflete as imperfeições do mercado de crédito com base em um contexto de assimetria de informação.

Segundo o modelo dos autores, os bancos escolhem o montante de recursos que irão emprestar de forma a maximizar os lucros, e não ultrapassam esse teto mesmo diante de um aumento das exigências, seja da taxa de juros ou do valor do colateral, já que isso aumentaria o risco do portfólio, podendo reduzir os lucros. A partir de então a literatura se dedicou em explicar as relações existentes entre as imperfeições no mercado de crédito e nível de desenvolvimento dos países. De forma geral, esses trabalhos estabelecem uma relação entre decisões de investimento e ocupacionais e as restrições de crédito que o agente enfrenta. Um resultado é, por exemplo, que pessoas mais habilidosas nem sempre conseguem empreender porque não conseguem os recursos necessários para tal. Assim, uma vez que o mercado não é perfeito, apenas os indivíduos mais ricos conseguem financiamento para se tornarem empreendedores, e os mais pobres irão tornar-se empregados assalariados. Nesta linha podemos destacar os trabalhos de Jovanovic (1989), Newman (1993) e Bernhardt (2000).

Partindo do pressuposto que as imperfeições do mercado de crédito não permitem que indivíduos com baixa riqueza consigam empréstimos para se tornarem empregadores, Newman (1993) argumentam que à distribuição inicial da riqueza explicaria as diferenças de nível de desenvolvimento e crescimento econômico dos países. Já para Bernhardt (2000), a distribuição inicial da riqueza determina apenas em um primeiro momento a escolha ocupacional dos agentes uma vez que, com o crescimento econômico, surgem rendimentos decrescentes de escala permitindo que indivíduos mais habilidosos, e, por isso mais 
eficientes, tornem-se empregadores, o que reduz o papel das restrições de crédito para determinação da estrutura ocupacional. O modelo de escolha ocupacional utilizado por Jovanovic (1989) considera a intensidade da restrição de liquidez como um parâmetro a ser estimado. Leth-Petrsen (2010), examina a importância da restrição do crédito para crescimento econômico da Dinamarca e seus efeitos sobre os gastos em consumo. O estudo indica que a reforma afetou majoritariamente os jovens e que houve um aumento do bemestar provocado pelo alargamento das possibilidades de consumo. Porém, considerando o agregado, o aumento do consumo e da dívida não foram significativos, e não afetaram as taxas de crescimento econômico. Já Ueda (2010) estima os ganhos no bem-estar da Tailândia promovidos pela liberalização financeira da metade da década de 80. O resultado é que, se a liberalização tem efeitos pequenos ou não significativos sobre o crescimento econômico mas os efeitos sobre o bem-estar são consideráveis

Tendo em vista que a disponibilidade de crédito afeta as escolhas dos indivíduos e o nível de desenvolvimento e crescimento econômico dos países vamos analisar como a existência do sistema legal pode implicar em uma restrição adicional para o mercado de empréstimos. Como podemos ver a identificação e entendimento de restrições de crédito se justifica por estar relacionada ao desenvolvimento dos países. Desta forma é relevante entendermos como o sistema legal pode implicar em uma restrição adicional. 


\section{O Modelo}

A seguir será exposto um modelo básico com o propósito de ilustrar como a existência de jurisprudência na tomada de decisão do juiz pode levar a uma situação em que o volume de crédito ofertado é maior. A cada período $t$ um contínuo de agentes privados, $I_{t}$, nasce. Estes agentes vivem por dois períodos de forma que serão considerados como jovens no primeiro período de vida e velhos no segundo. Sendo assim, em um dado instante de tempo $t$, exceto para o primeiro e para o último, temos $I_{t}$ agentes novos, denotaremos estes por $i$, e $O_{t}$ agentes velhos, $o$. Além disso, não existe crescimento populacional, ou seja, o número de jovens que nasce é o mesmo para todo período que é o mesmo de velhos. A cada período de vida os agentes, velhos e novos, recebem uma dotação de renda que pode ser alta ou baixa. Os agentes jovens observam a renda que receberam e decidem se ofertarão ou demandarão empréstimos. A decisão do agente é poupar ou emprestar a fim de maximizar o valor presente da utilidade no primeiro e segundo período. Sendo assim um jovem que recebe renda baixa ao nascer desejaria tomar emprestado vislumbrando a possibilidade de ter renda alta quando for velho. Por outro lado um agente que nasce e recebe renda alta estaria disposto a emprestar parte de sua renda a fim de aumentar consumo futuro. Caso não houvesse nenhum outro ingrediente o equilíbrio do mercado seria dado por uma taxa de juros que igualasse oferta e demanda, para esta situação daremos o nome de escolha irrestrita. No entanto, sem observar a renda individual um juiz decide se os empréstimos feitos no período anterior serão pagos ou não. O objetivo da decisão do juiz é maximizar sua função de bem estar que depende do bem estar social e de um componente legal. Após a decisão judicial os agentes nascidos no período atual decidem, com base em sua renda e com a informação da decisão judicial, o montante de empréstimos ótimo. Para um melhor entendimento podemos ver a cronologia dos eventos na figura 1 apresentada a seguir.

Na próxima seção, 2.1, será exposta a resolução para a situação que donimamos a pouco como escolha ótima irrestrita. Na seção 2.2 abordaremos o caso em os agentes se deparam com uma restrição, de forma que os empréstimos que excederem tal restrição não serão 


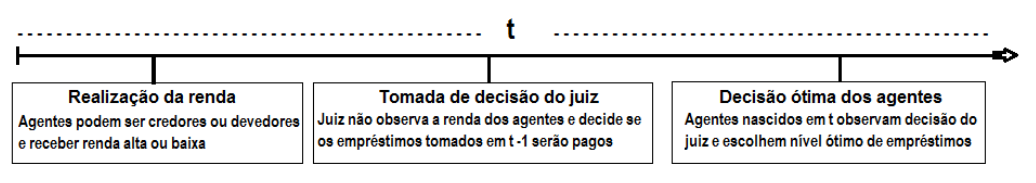

Figure 1: Cronologia dos eventos

pagos. A decisão de determinar o calote ou o pagamento vem de um agente judicial que tem como objetivo maximizar sua função de bem estar. Como veremos na seção 2.3 a função de bem estar do juiz consiste na soma descontada da utilidade dos agentes e em um componente de jurisprudência. Em 2.4 observaremos que o juiz enfrenta um trade-off na medida que ao determinar o calote aumenta a utilidade agregada dos velhos mas reduz a dos jovens ao reduzir o montande de empréstimos feitos. Na secão 2.5 abordaremos a determinação da taxa de juros de equilíbrio em um ambiente conforme o sugerido, bem como o montante de empréstimos ofertado pelos agentes. Na seção 2.6 daremos atenção à solução recursiva do modelo. Em 2.7 será abordada a relação entre jurisprudência e o volume de crédito. Na seção 2.8 por sua vez focaremos na relação entre a taxa de juros de equilíbrio e a jurisprudência. Por fim em 2.9 apresentaremos resultados numéricos para o modelo proposto gerados no Matlab.

\section{2..1 Escolha Ótima dos Agentes Irrestritos}

A cada período de tempo $t$ os agentes, tanto velhos quanto novos, recebem uma dotação de renda que pode ser alta ou baixa. Vamos considerar que a cada período $\theta$ agentes novos e velhos recebam renda alta. Normalizando o tamanho de $O$ e $I$ para unidade temos que $\theta$ agentes recebem renda alta e que $1-\theta$ recebem renda baixa. Desta forma a probabilidade de um velho receber renda alta em um dado período é a mesma que a de um jovem. Ao passo que com probabilidade $1-\theta$ um dado agente recebe renda baixa. Dada sua renda ao nascer o agente decide emprestar ou tomar empréstimos com o objetivo de maximizar a soma da sua utilidade do consumo em $t$ e $t+1$. O que motiva um jovem de renda baixa a tomar empréstimos é o fato de que no futuro sua renda não será menor do que a 
atual, de forma que a utilidade marginal futura esperada da renda não é menor do que a utilidade marginal presente. De maneira similar um agente que recebe renda alta quando jovem tem interesse em ofertar empréstimos.

Vamos denotar por $b_{i}$ o montante de dívida, caso seja negativo, ou de empréstimos, caso seja positivo, feitos por um jovem e que devem ser pagos ou recebidos no próximo período quando este agente for velho. Vamos considerar que os empréstimos só podem ser feitos entre agentes da mesma geração, ou seja, não podemos ter em um mesmo instante de tempo $t$ transações entre jovens e velhos. O problema dos jovens é, dada sua renda no primeiro período, escolher $b_{i}$ de tal sorte que maximize a utilidade do consumo presente e a utilidade esperada do consumo futuro, descontada por um fator de desconto $\beta$. Sendo assim o problema do agente $i$, nascido em $t$, é escolher $b_{i}$ a fim de:

$$
\begin{gathered}
\operatorname{Maxu}\left(c_{i, t}\right)+\beta E\left[u\left(c_{i, t+1}\right)\right] \\
\text { Sujeito a: } \\
c_{i, t}=W_{i, t}-b_{i} \\
c_{i, t+1}=W_{H}+b_{i} R_{t} \text { com probabilidade } \theta \\
c_{i, t+1}=W_{L}+b_{i} R_{t} \text { com probabilidade } 1-\theta
\end{gathered}
$$

O nível de empréstimo que é ótimo para o agente $i, b_{i}^{*}$, deve ser tal que satisfaça a seguinte condição de primeira ordem:

$$
u^{\prime}\left(c_{i, t}\right)=\beta E\left[u^{\prime}\left(c_{i, t+1}\right)\right] R_{t}
$$

Sendo $u($.$) uma função estritamente côncava devemos ter que b_{i}<0$ para o agente que tem renda baixa quando nasce, e $b_{i}>0$ para o agente que teve renda alta. Para ver isto note que se $u($.$) é uma função estritamente côncava, então u^{\prime}($.$) é monótona decrescente.$ Considere agora o agente que recebe renda alta ao nascer. Tomando $b_{i}=0$ e para $R_{t}$ tal que $R_{t} \beta=1$ temos que: 


$$
u^{\prime}\left(W_{H}-b_{i}\right)<\left[\theta u^{\prime}\left(W_{H}+b_{i} R_{t}\right)+(1-\theta) u^{\prime}\left(W_{L}+b_{i} R_{t}\right)\right] R_{t} \beta
$$

Por outro lado tomando $b_{i}$ suficientemente grande temos que :

$$
u^{\prime}\left(W_{H}-b_{i}\right)>\left[\theta u^{\prime}\left(W_{H}+b_{i} R_{t}\right)+(1-\theta) u^{\prime}\left(W_{L}+b_{i} R_{t}\right)\right] R_{t} \beta
$$

Portanto $b_{i}^{*}$ que satisfaz a condição de primeira ordem para uma agente que teve renda ao nascer dever ser maior que zero. Procedendo de maneira análoga, chegamos à conclusão de que $b_{i}^{*}<0$ para o agente que tem renda baixa quando nasce. Note que os velhos não resolvem nenhum problema de maximização. A utilidade dos velhos é dada por :

$$
u\left(c_{o, t}\right)=u\left(W_{o}+b_{o} R_{t-1}\right)
$$

Como podemos observar ela depende fundamentalmente de dois componentes: a dívida que eles devem pagar e da renda que recebem. Note que $b_{o}=b_{i_{t-1}}$ e já foi decidido no período passando quando estes agentes eram jovens. Por outro lado a renda é dada exogenamente.

\section{2..2 Escolha Ótima dos Agentes Restritos}

Imagine agora que o pagamento dos empréstimos esteja sujeito à uma condição: empréstimos maiores que um determinado valor não serão pagos. O que acontece é que no segundo período de vida dos agentes um juiz determinará se os empréstimos tomados no primeiro período devem ser pagos ou não. Note que para um agente de renda baixa a restrição não é um problema, não diretamente, uma vez que para ele o melhor seria de fato não pagar. Por outro lado o agente de renda alta sabe que se emprestar além de um determinado valor, digamos $b_{J, t+1}$, ele não receberá no próximo período. Desta maneira em um ambiente restrito os agentes de renda alta ofertam o mínimo, para um dada taxa de juros, entre o valor que resolve o problema irrestrito, digamos $b^{*}$, e $b_{J, t+1}$. Vale ressaltar que a restrição imposta ao montante de empréstimos escolhido pelos agentes de renda alta 
acaba por interferir na escolha dos agentes de renda baixa, uma vez que estes podem não ter acesso ao montante ótimo de empréstimos para eles, uma vez que dependendo deste valor ninguém estaria disposto a emprestar.

\section{2..3 O Agente Judiciário}

Como sugerimos na última seção, os empréstimos efetuados têm seu pagamento determinado por um juiz, digamos $j$. Vamos considerar que o juiz decide se os empréstimos devem ser pagos sem observar a renda individual dos agentes. Vamos considerar que a variável de escolha do juiz seja uma variável binária e seja denotada por $d_{t}$. Quando o juiz opta por $d_{t}=1$ ele está escolhendo por forçar o pagamento. Caso opte por $d_{t}=0$ estaria permitindo o calote. Ao tomar esta decisão o juiz busca maximizar uma função de utilidade que depende fundamentalmente de dois termos. O valor presente da soma das utilidades dos agentes e um componente legal, $K$, que depende da decisão judicial passada, $d_{t-1}$, e de uma recomendação legal, $d^{*}$. A seguir veremos em detalhes como $K$ é definido:

$$
K=k\left(d^{*}-d_{t}\right)^{2}(1-\gamma)+k\left(d_{t}-d_{t-1}\right)^{2} \gamma
$$

Podemos ver $\gamma$ como a ênfase da jurisprudência e $k$ o custo de o juiz divergir da recomendação legal ou da decisão passada. Note que quando $\gamma=0$ estamos em um regime onde apenas o código importa para o juiz, já que $K$ é dado por:

$$
K=k\left(d^{*}-d_{t}\right)^{2}
$$

Considere agora o caso em que $\gamma=1$. Neste caso o componente legal resume-se ao termo de desvio da decisão passada, ou seja, resume-se ao termo de jurisprudência como podemos ver a seguir: 


$$
K=k\left(d_{t}-d_{t-1}\right)^{2}
$$

Uma vez definido o componente legal, vamos agora definir a função de bem estar do juiz , que é dada por:

$$
H_{j}\left(d_{t} \mid d_{t-1}\right)=\sum_{t=t_{0}}^{T} \beta^{t-t_{0}} E\left[\sum_{o} \alpha_{o} u\left(c_{o, t}\left(d_{t}\right)\right)+\sum_{i} \alpha_{i} u\left(c_{i, t}\left(d_{t}\right)\right)\right]-K
$$

Em que $\alpha_{i}$ é o tamanho de jovens do tipo $i$, que podem ser de dois tipos: $H$ ou $L$. Quando um agente jovem recebe renda alta, $W_{H}$, vamos dizer que o tipo dele é dado por $\mathrm{H}$ e quando sua renda for baixa, $W_{L}$ temos $i=L$. Analogamente, $\alpha_{o}$ é o tamanho do grupo de velhos do tipo o. Sendo que estes podem ser de quatro tipos: agentes que tiveram renda alta nos dois períodos, outro dos que tiveram renda alta ao nascer e baixa na sequência, um terceiro contendo os que tiveram renda baixa e alta e por fim um quarto grupo; com os agentes que tiveram renda baixa nos dois períodos de vida. Denotaremos estes grupos respectivamente por: $H|H, L| H, H \mid L$ e $L \mid L$.

Como podemos observar acima o consumo dos velhos é função da decisão judicial em $t$ e $t-1$. O que acontece é que quando o juiz opta pelo calote o consumo dos agentes devedores é maior do que seria uma vez que não devem mais pagar suas dívidas. Por outro lado, o consumo dos agentes que teriam o direito de receber é menor. Desta forma temos que $c_{o}$ depende diretamente de $d_{t}{ }^{3}$. Além disso, o consumo dos velhos depende também da decisão que foi tomada em $t-1$ uma vez que esta decisão aumenta o custo de se tomar uma decisão diferente neste período. Sendo assim temos:

$$
c_{o, t}\left(d_{t}, d_{t-1}\right)=W_{o, t}+b_{o} R_{t-1} d_{t}
$$

Vamos analisar agora a relação entre a decisão judicial no instante $t$ e o consumo dos agentes nascidos no mesmo instante, os jovens. O consumo destes agentes é dado por:

\footnotetext{
${ }^{3}$ Para o caso em que temos apenas duas possibilidades de renda existe apenas um tipo de julgamento, com os credores sendo os agentes de renda alta e os devedores o de renda baixa, desta forma todos os casos são iguais e, sendo os juízes iguais, podemos resolver para todos casos conjuntamente
} 


$$
c_{i, t}\left(d_{t}\right)=W_{i, t}-b_{i}
$$

Aparentemente a decisão judicial não influência no consumo destes agentes. No entanto, ao tomar uma decisão hoje o juiz implica em um custo para que outra decisão seja tomada amanhã, refletido por $K$. O que acontece é que ao tomar uma decisão hoje, o juiz estaria se comprometendo, em alguma medida, a tomar a mesma decisão amanhã já que aumenta seu custo de tomar uma decisão diferente. Isto faz com que o valor de $b_{J, t+1}$ para a partir do qual o juiz determina o calote seja afetado. Desta forma podemos escrever $c_{i, t}$ como função de $d_{t}$ tal como foi feito acima. Como podemos observar a utilidade do juiz depende fundamentalmente de três termos: utilidade dos jovens, utilidade dos velhos e do componente legal. Para fins didáticos iremos inicialmente analisar o que acontece e como o modelo se desenrola para o caso em que temos $\gamma=1$. Desta forma estaremos considerando a seguinte forma funcional:

$$
H_{j}\left(d_{t} \mid d_{t-1}\right)=\sum_{t=t_{0}}^{T} \beta^{t-t_{0}} E\left[\sum_{o} \alpha_{o} u\left(c_{o, t}\left(d_{t}\right)\right)+\sum_{i} \alpha_{i} u\left(c_{i, t}\left(d_{t}\right)\right)\right]-k\left(d_{t}-d_{t-1}\right)^{2}
$$

\section{2..4 A Tomada de Decisão do Judiciário: O Efeito da Jurisprudência}

Como dito, o juiz não observa a renda individual dos agentes ao tomar sua decisão. Desta forma, do ponto de vista do juiz, ele não sabe se o agente devedor teve renda baixa ou alta no período em que deve efetuar o pagamento. A única informação sobre a renda dos agentes disponível para o juiz é a parcela de agentes que recebe renda alta e de agentes que recebe renda baixa a cada período, ou seja, o valor de $\theta$. Adicionalmente, note que a parcela de agentes que recebe renda alta quando velhos deve ser igual a soma a parcela de agentes dos tipos $H \mid H$ e $H \mid L$, ou seja:

$$
\alpha_{H \mid L}+\alpha_{H \mid H}=\alpha_{H}=\theta
$$

De maneira análoga devemos ter que:

$$
\alpha_{L \mid L}+\alpha_{L \mid H}=\alpha_{L}=1-\theta
$$


Mas sendo $\theta$ uma constante devemos ter que a parcela de agentes que tiveram renda alta quando jovens e que têm renda baixa agora mais a parcela dos que têm e tiveram renda alta deve ser igual a $\theta$. Da mesma forma a parcela de agentes que tiveram renda baixa em $t-1, \alpha_{L}$, deve ser igual a soma dos que tiveram renda baixa e têm renda alta mais a parcela dos que continuam a ter renda baixa. Desta forma as seguintes igualdades também devem ser válidas:

$$
\begin{gathered}
\alpha_{L \mid H}+\alpha_{H \mid H}=\theta \\
\alpha_{H \mid L}+\alpha_{L \mid L}=1-\theta
\end{gathered}
$$

Combinando-as, temos que

$$
\alpha_{L \mid H}+\alpha_{H \mid H}=\alpha_{H \mid L}+\alpha_{H \mid H}
$$

e portanto:

$$
\alpha_{H \mid L}=\alpha_{L \mid H}
$$

Juntando isto ao fato de que

$$
\alpha_{H}=1-\alpha_{L}
$$

Temos que as seguintes relações devem ser válidas:

$$
\begin{gathered}
\alpha_{H \mid H}=\alpha_{H}-\alpha_{L \mid H} \\
\alpha_{L \mid L}=1-2 \alpha_{H}+\alpha_{H \mid H}
\end{gathered}
$$

Como dito anteriormente, a única informação disponível para o juiz é o valor de $\theta$. Como podemos ver acima isto nos deixa com duas equações e três incógnitas dando margem a mais de uma solução. Note que pode acontecer uma situação em que todos os agentes que tiveram renda alta no período anterior terem uma renda baixa neste período, ou seja, implicando 


$$
\alpha_{H \mid L}=\theta \text { e } \alpha_{L \mid L}=1-2 \theta
$$

No entanto pode ocorrer outra situação que seja, por exemplo, o oposto desta. Com $\alpha_{H \mid H}=\theta$ e portanto:

$$
\alpha_{H \mid L}=0 \text { e } \alpha_{L \mid L}=1-\theta=\alpha_{L}
$$

Desta forma, como o juiz não observa a renda individualmente ele deve considerar todos os casos possíveis ponderando-os pelas respectivas probabilidades. Denotando por $s \mathrm{um}$ possível caso temos que:

$$
E\left[\sum_{o} \alpha_{o} u\left(c_{o, t}\left(d_{t}\right)\right)\right]=\sum_{s} p(s) \sum_{o} \alpha_{o}(s) u\left(c_{o, t}\left(d_{t}\right)\right)
$$

De forma que para todo $s$, caso, as seguintes igualdades devem valer:

$$
\begin{gathered}
\alpha_{L \mid H}(s)=\alpha_{H \mid L}(s)=\theta-\alpha_{H \mid H}(s) \\
\alpha_{L \mid L}(s)=1-2 \theta+\alpha_{H \mid H}(s) \\
\alpha_{H}(s)+\alpha_{L}(s)=1
\end{gathered}
$$

Por fim devemos analisar o termo $E\left[\sum_{i} \alpha_{i} u\left(c_{i, t}\left(d_{t}\right)\right)\right]$. Como o juiz sabe que $\alpha_{H}$ agentes têm renda alta e gozando das informações referente ao problema de maximização do agente, ele sabe com certeza que $\alpha_{H}$ agentes do tipo renda alta ofertarão empréstimos escolhendo $b_{i=H}^{*}>0$ e $\alpha_{L}$ tomarão empréstimos escolhendo $b_{i=L}^{*}<0$. Sendo asism, temos que

$$
E\left[\sum_{i} \alpha_{i} u\left(c_{i, t}\left(d_{t}\right)\right)\right]=\alpha_{H} u\left(c_{i=H, t}\left(d_{t}\right)\right)+\alpha_{L} u\left(c_{i=L, t}\left(d_{t}\right)\right)
$$

De forma que:

$$
c_{i=H, t}\left(d_{t}\right)=W_{t, H}+b_{i=H}^{*}
$$




$$
c_{i=L, t}\left(d_{t}\right)=W_{t, L}+b_{i=L}^{*}
$$

Como podemos observar, o juiz enfrenta um trade-off entre aumentar utilidade esperada dos velhos e reduzir a utilidade dos jovens em um dado instante de tempo. Para ver isto considere um caso em que tenhamos dois agentes. Como o juiz não sabe qual dos velhos recebeu renda alta, credor ou devedor, ele sempre acha melhor ordenar o calote uma vez que em termos esperados a utilidade esperada do calote é sempre maior que a do pagamento. Para ver isto basta notar que do ponto de vista judicial quando ele ordena o pagamento ele gera uma mean preserving spread da distribuição original o que faz com que a soma das utilidades esperadas seja sempre maior para o caso em que o juiz escolhe o calote. Sendo assim temos que para qualquer $b_{o}>0$

$$
E\left[\sum_{o} \alpha_{o} u\left(W_{o, t}+b_{o} R_{t-1}\right)\right]<E\left[\sum_{o} \alpha_{o} u\left(W_{o, t}\right)\right]
$$

Ao escolher $d_{t}=1$ o juiz estaria apenas gerando mais dispersão na distribuição sem alterar a média o que faz com que sua utilidade seja menor neste termo. Para ver isto mais facilmente tome $b_{o} R_{t-1}$ suficientemente grande, então sendo $u($.$) uma função estritamente$ côncava devemos ter que vale a desigualdade acima. Considere agora a situação dos jovens. Embora o juiz não saiba a renda individual, ele sabe que os jovens que tomarão empréstimos serão os de renda baixa, ao passo que os jovens de renda alta desejarão ofertar empréstimos. Além disso, o montante de empréstimos que os agentes escolhem é função direta da decisão judicial hoje, de forma que quando o juiz determina o calote hoje ele implica que menos empréstimos serão ofertados pelos jovens hoje. Desta forma o mercado de empréstimos é restringido, implicando em menos benefícios de redistribuição entre os jovens de renda alta e os de baixa. Sendo assim temos que a seguinte desigualde é válida:

$$
E\left[\sum_{i} \alpha_{i} u\left(c_{i, t}\left(d_{t}=1\right)\right)\right]>E\left[\sum_{i} u\left(c_{i, t}\left(d_{t}=0\right)\right)\right]
$$

Ou seja, o juiz ao escolher pelo pagamento sempre aumentará a soma da utilidade esperada 
dos jovens, ao contrário, do que acontece com a utilidade dos velhos. Sendo assim temos que um dos termos depende positivamente de $d_{t}$ e outro negativamente.

Vamos prosseguir agora com a formulação recursiva do problema. Podemos escrever o problema da seguinte forma:

$$
V\left(d_{t}\right)=\operatorname{Max}_{\left[d_{t}\right]_{t_{0}}^{T}} H(.)
$$

onde

$$
H_{j}\left(d_{t} \mid d_{t-1}\right)=\sum_{t=t_{0}}^{T} \beta^{t-t_{0}} E\left[\sum_{o} \alpha_{o} u\left(c_{o, t}\left(d_{t}\right)\right)+\sum_{i} \alpha_{i} u\left(c_{i, t}\left(d_{t}\right)\right)\right]-k\left(d_{t}-d_{t-1}\right)^{2}
$$

Então sendo

$$
h_{j, t}\left(d_{t} \mid d_{t-1}\right)=E\left[\sum_{o} \alpha_{o} u\left(c_{o, t}\right)+\sum_{i} \alpha_{i} u\left(c_{i, t}\right)\right]-k\left(d_{t}-d_{t-1}\right)^{2}
$$

Podemos reescrever o problema de otimização do juiz da seguinte forma:

$$
V\left(d_{t}, b_{o}\right)=\operatorname{Max}_{\left[d_{t}\right]_{t_{0}}^{T}}\left[h_{j, t}\left(d_{t} \mid d_{t-1}\right)+\beta E_{t}\left[V\left(d_{t+1}, b_{i}\right)\right]\right]
$$

Note que o juiz tem apenas duas opções. Optar por $d_{t}=1$ ou $d_{t}=0$. Desta forma a função valor é igual ao máximo entre as duas opções de escolha, ou seja, podemos reescrever a função valor como:

$$
\begin{gathered}
V\left(d_{t}, b_{o}\right)=\operatorname{Max}\left[h_{j, t}\left(d_{t}=1 \mid d_{t-1}\right)+\beta E_{t} V\left(d_{t+1}, b_{i} \mid d_{t}=1\right),\right. \\
\left.\mathrm{h}_{j, t}\left(d_{t}=0 \mid d_{t-1}\right)+\beta E_{t} V\left(d_{t+1}, b_{i} \mid d_{t}=0\right)\right]
\end{gathered}
$$

Desta forma o juiz opta por $d_{t}=1$ quando: 


$$
\begin{gathered}
h_{j, t}\left(d_{t}=1 \mid d_{t-1}\right)+\beta E_{t}\left[V\left(d_{t+1}, b_{i} \mid d_{t}=1\right)\right] \geq \\
\mathrm{h}_{j, t}\left(d_{t}=0 \mid d_{t-1}\right)+\beta E_{t}\left[V\left(d_{t+1}, b_{i} \mid d_{t}=0\right)\right]
\end{gathered}
$$

\section{2..5 Juros e Empréstimos de Equilíbrio.}

Em um ambiente de informação completa e com agentes agindo racionalmente devemos ter que o nível de empréstimos que um agente de renda alta vai escolher ofertar no primeiro período de vida deve ser tal que o juiz não tenha interesse em ordenar o calote. Desta forma o agente $i$ observa $d_{t}$ e antecipa a maneira como o juiz tomará sua decisão no próximo período e então, dado isso, escolhe um nível de empréstimos que faça com que a utilidade do juiz em dar calote não seja maior do que optando por forçar o pagamento. Desta forma o problema do agente $i$ é escolher $b_{i}$ a fim de:

$$
\operatorname{Max}\left(u\left(c_{i, t}\right)+E_{t+1} \beta u\left(c_{i, t+1}\right)\right)
$$

Sujeito a:

$$
\begin{gathered}
c_{i, t}=W_{i, t}-b_{i} \\
c_{i, t+1}=W_{i, t+1}+b_{o} R_{t}
\end{gathered}
$$

E a restrição adicional, que denotaremos como restrição judicial:

$$
\begin{array}{r}
E\left[h_{j, t+1}\left(d_{t+1}=1 \mid d_{t}\right)+\beta V\left(d_{t+2}, b_{i} \mid d_{t+1}=1\right)\right] \geq \\
\mathrm{E}\left[\mathrm{h}_{j, t+1}\left(d_{t+1}=0 \mid d_{t}\right)+\beta V\left(d_{t+2}, b_{i} \mid d_{t+1}=0\right)\right]
\end{array}
$$


Sendo $b_{J, t+1}$ o nível de empréstimos tal que a restrição judicial valha com igualdade, então para qualquer,$b_{i} \leq b_{J, t+1}$ a desigualdade acima é satisfeita. Para ver isto note primeiramente que o termo $\beta V\left(d_{t+2}, b_{i} \mid d_{t+1}\right)$ independe de $b_{o}$. Agora observe que:

$$
h_{j, t+1}\left(d_{t+1} \mid d_{t}\right)=E_{t+1}\left[\sum_{o} \alpha_{o} u\left(c_{o, t+1}\right)+\sum_{i} \alpha_{i} u\left(c_{i, t+1}\right)\right]-k\left(d_{t+1}-d_{t}\right)^{2}
$$

Como podemos ver, os termos $k\left(d_{t+1}-d_{t}\right)^{2}$ e $E\left[\sum_{i} \alpha_{i} u\left(c_{i, t+1}\right)\right]$ também não dependem de $b_{o}$ o que nos deixa apenas com o termo $E_{t+1}\left[\sum_{o} u\left(c_{o, t+1}\right)\right]$ para analisar. Mas lembre que para $d_{t+1}=1$ :

$$
E\left[\sum_{i} \alpha_{o} u\left(c_{o, t+1}\right)\right]=E\left[\sum_{o} \alpha_{o} u\left(W_{o, t+1}+b_{o} R_{t+1}\right)\right]
$$

Por fim note que o termo acima é decrescente em $b_{o} R_{t+1}$, portanto qualquer $b_{o} R_{t+1} \leq$ $b_{J, t+1} R^{J}$ satisfaz a restrição judicial. De forma que podemos reescrevê-la simplesmente como:

$$
b_{o} R_{t+1} \leq b_{J, t+1} R^{J}
$$

Além disso, ainda devemos analisar se a restrição é ativa ou não. No fundo o que estamos interessados em saber é se o nível ótimo de empréstimos quando o agente não está restrito é maior do que o tolerado pela autoridade judicial. Obviamente, o nível de empréstimos ótimo que o agente de renda alta decide ofertar, é uma função crescente dos juros enquanto o nível de empréstimos demandado pelo agente de renda baixa é função decrescente. Desta forma em um ambiente irrestrito temos uma taxa de juros, digamos $R^{*}$, tal que equilíbre o mercado de empréstimos de forma que a oferta seja igual a demanda. Sendo assim para a taxa de juros $R^{*}$ temos um nível de empréstimos de equilíbrio que denotaremos por $b^{*}$. A figura 2 retrata este equilíbrio irrestrito.

Agora considere o equilíbrio em um ambiente restrito. Sendo $b_{J, t+1}$ uma função decrescente dos juros, devemos ter que existe uma taxa de juros, digamos $R^{J}$, tal que o nível 


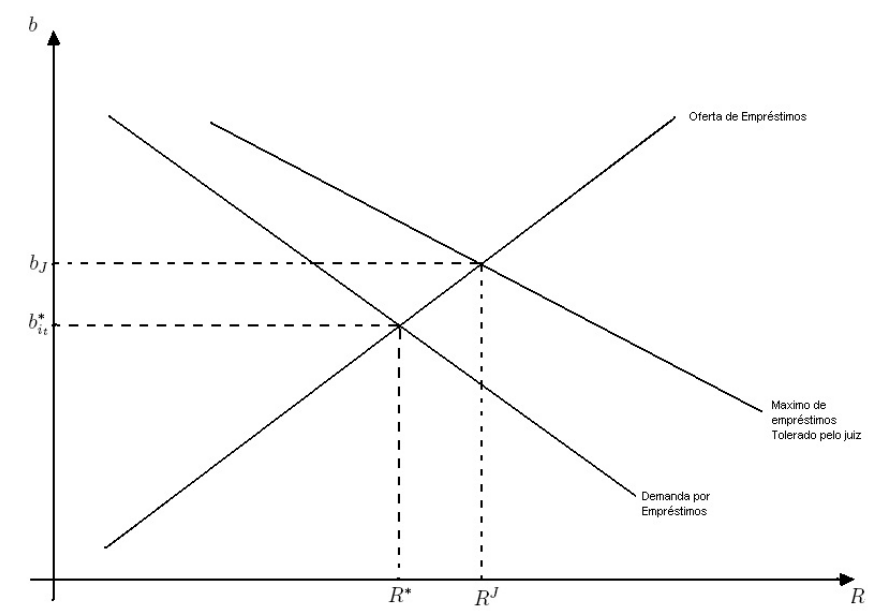

Figure 2: Situação irrestrita

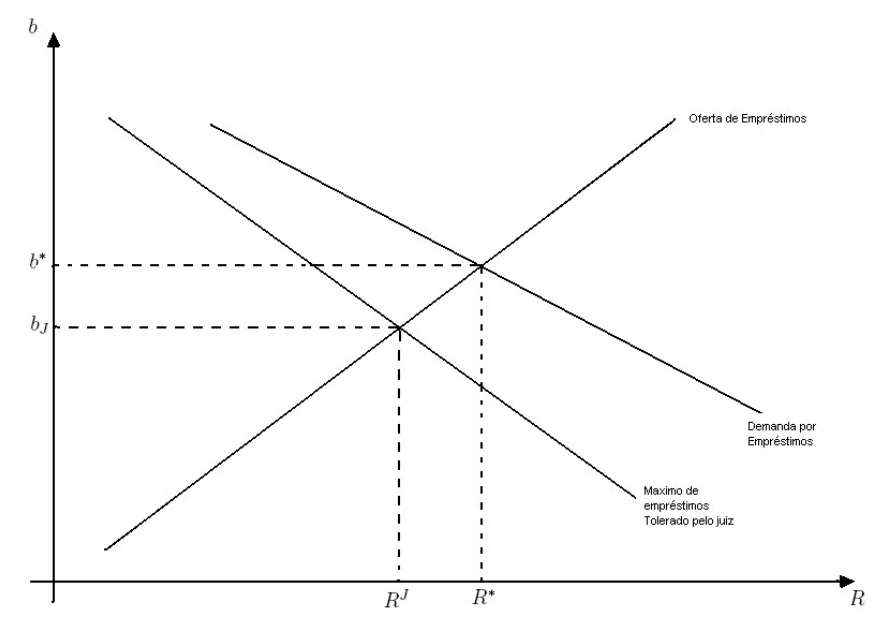

Figure 3: Situação restrita

de empréstimos ótimo que o agente de renda alta decide ofertar seja igual ao nível de empréstimos para o qual, dado $R^{J}$, o juiz é indiferente entre o calote e o pagamento. Denotaremos este por $b_{J^{*}, t+1}$. O que o agente de renda alta faz quando nasce é verificar se o nível de empréstimos de equilíbrio para o ambiente irrestrito, $b^{*}$, é maior ou menor que o nível de empréstimos tolerado pelo juiz, ou seja, que $b_{J^{*}, t+1}$. Caso $b_{J^{*}, t+1}<b^{*}$ o agente decide ofertar $b_{J^{*}, t+1}$ à taxa de juros $R^{J}$, o que por sua vez acaba limitando a quantidade de empréstimos que o agente de renda baixa pode tomar. Caso contrário, não existe problema em escolher o nível ótimo da situação irrestrita e o mercado se equilibra à taxa de juros $R^{*}$ e com uma oferta de empréstimos igual a demanda. Note ainda que 
quando o agente está restrito, ou seja, decide ofertar $b_{J^{*}, t+1}$, temos uma situação em que o volume de crédito é menor do que seria o ótimo assim como a taxa de juros. Na figura 3 podemos visualizar esta situação.

\section{2..6 Resolvendo o Modelo}

Vamos considerar agora a maneira como resolveremos o modelo. A estratégia para resolução será resolver de traz para frente e interando a função valor até que convirja. Começaremos pelo instante terminal, ou seja, $t=T$. Note que neste nenhum agente nasce. Sendo assim dado $d_{t-1}$ a utilidade do juiz quando ele opta pelo pagameto é dada por:

$$
h_{j, T}\left(d_{T}=1 \mid d_{T-1}\right)=E\left[\sum_{o} \alpha_{o} u\left(c_{o, T}\right)-k\left(1-d_{T-1}\right)^{2}\right]
$$

Por outro lado quando ele opta pelo calote sua utilidade é dada por:

$$
h_{j, T}\left(d_{T}=0 \mid d_{T-1}\right)=E\left[\sum_{o} \alpha_{o} u\left(c_{o, T}\right)\right]-k\left(-d_{T-1}\right)^{2}
$$

Em que

$$
c_{o, T}=W_{o, T}+b_{o} R_{T} d_{T}
$$

A fim de tornar simples a notação vamos denotar $h_{j, t}\left(d_{t} \mid d_{t-1}\right)$ por $h_{d_{t} \mid d_{t-1}}$. Sendo assim, $h_{d_{t} \mid d_{t-1}}$ é a utilidade do juiz $j$ de escolher $d_{t}$ no instante $t$ dado uma decisão $d_{t-1}$ em $t-1$. Note que um agente nascido, e com renda alta, em $T-1$ vai escolher $b_{H}^{*}$ de tal sorte que

$$
b_{H}^{*}=\min \left[b_{J^{*}, T}, b^{*}\right]
$$

Onde $b_{J *, T}$ é o montante de empréstimos que torna o juiz indiferente entre permitir o calote e determinar o pagamento à uma dada taxa de juros $R^{J}$ e $b^{*}$ é o nível de empréstimo ótimo para o caso em que não existe juiz. Sendo assim a função valor, $V_{t}($.$) , no instante de tempo$ $t=T$ dado $d_{T-1}$ é dada por: 


$$
V_{T}\left(d_{T}, b_{T} \mid d_{T-1}\right)=\operatorname{Max}\left[h_{d_{T}=1 \mid d_{T-1}}, h_{d_{T}=0 \mid d_{T-1}}\right]
$$

Agora considere a decisão judicial no peródo $t=T-1$. Dado $d_{T-2}$ a utilidade do juiz quando ele opta pelo pagameto é dada por:

$$
h_{d_{T-1} \mid d_{T-2}}=E\left[\sum_{o} \alpha_{o} u_{o}\left(c_{o, T-1}\right)+\sum_{i} \alpha_{i} u_{i}\left(c_{i, T-1}\right)\right]-k\left(1-d_{T-2}\right)^{2}
$$

Note que a única coisa que difere a utilidade do juiz em $t=T$ e neste período é o termo $E\left[\sum_{i} \alpha_{i} u_{i}\left(c_{i, T}\right)\right]$. A razão pela qual este termo surgiu é que em $T$ não nasciam novos agentes. Agora para $t<T$ nascem agentes que ofertam e demandam empréstimos visando pagar ou receber em $t+1$. Além disso, o montante de empréstimos que são ofertados em $T-1$ dependem da decisão judicial em $t=T-1$. Note que caso não existisse custo algum de desviar do precedente, caso tivessemos $k=0$, este termo não apareceria como argumentamos anteriormente. Por outro lado, quando o juiz opta pelo calote sua utilidade é dada por:

$$
h_{d_{T-1}=0 \mid d_{T-2}}=E\left[\sum_{o} \alpha_{o} u_{o}\left(c_{o, T-1}\right)+\sum_{i} \alpha_{i} u\left(c_{i, T-1}\right)\right]-k\left(-d_{T-2}\right)^{2}
$$

Note que um agente nascido, e que teve renda alta, em $T-2$, escolheu $b_{H}$ de tal sorte que

$$
b_{H}=\min \left[b_{J *, T-1}, b^{*}\right]
$$

Sendo assim a função valor, $V($.$) , no instante de tempo t=T-1$ dado $d_{t-2}$ é dada por:

$$
\begin{gathered}
V\left(d_{T-1}, b_{T-1}\right)=\operatorname{Max} E_{T-1}\left[h_{d_{T-1}=1 \mid d_{T-2}}+\beta V\left(d_{T}, b_{T} \mid d_{T-1}=1\right),\right. \\
\left.\mathrm{h}_{d_{T-1}=0 \mid d_{T-2}}+\beta V\left(d_{T}, b_{T} \mid d_{T-1}=0\right)\right]
\end{gathered}
$$

Então, para resolver o modelo continuaremos com esses passos e avaliando a função valor até que esta convirja. 


\section{2..7 Jurisprudência e o Volume de Crédito}

Vamos definir agora alguns resultados gerais. Primeiro vamos analisar o que acontece com o caso em que $k=0$. Neste caso o juiz sempre escolherá o calote. Para ver isto note que quando $k=0$ o juiz não considera o efeito de sua decisão sobre os empréstimos que os jovens tomam e o juiz considera apenas o seguinte termo na hora de decidir:

$$
E\left[\sum_{o} \alpha_{o} u_{o}\left(c_{o, t}\right)\right]
$$

Desta forma $h($.$) é dada por:$

$$
h_{j, t}\left(d_{t} \mid d_{t-1}\right)=E\left[\sum_{o} \alpha_{o} u_{o}\left(c_{o}\right)\right]
$$

Em que:

$$
c_{o, t}=W_{o, t}+b_{o} R_{t} d_{t}
$$

Note que para qualquer $b_{o}>0$ temos que $h_{j, t}\left(d_{t}=0 \mid d_{t-1}\right)>h_{j, t}\left(d_{t}=1 \mid d_{t-1}\right)$. Para ver isso note que:

$$
h_{j, t}\left(d_{t}=0\right)=E \sum_{o}\left[\alpha_{o} u_{o}\left(W_{o, t}\right)\right]>E \sum_{o}\left[\alpha_{o} u_{o}\left(W_{o, t}+b_{o} R_{T}\right)\right]=h_{j, t}\left(d_{t}=1\right)
$$

Isso por que $E \sum_{o} \alpha_{o} W_{o, t}=E \sum_{o} \alpha_{o}\left(W_{o, t}+b_{o} R_{t}\right)$ já que o equilíbrio no mercado de crédito requer que $\sum_{o} \alpha_{o} b_{o}=0$, ou seja, do ponto de vista do juiz ordenar o pagamento implica em uma alocação de consumo que é Mean Preserving Spread da alocação que resulta do calote. Desta forma com $k=0$ o juiz sempre prefere o calote.

Considere agora que $k>0$. Neste caso o calote nunca será uma decisão de equilíbrio. Como vimos ao resolver o problema de maximização dos agentes a tomada de decisão do judiciário é antecipada pelos agentes de forma que o calote nunca ocorre em equilíbrio. Para ver isso note que o agente $i$ prefere emprestar nada do que emprestar algo e não receber, basta ver que para qualquer $b_{i}>0$ : 


$$
u\left(W_{H, t}-b_{i}\right)+\beta E\left[u\left(W_{i, t+1}\right)\right]<\mathrm{u}\left(\mathrm{W}_{H, t}\right)+\beta E\left[u\left(W_{i, t+1}\right)\right]
$$

Sendo assim o agente $i$ que teve renda alta prefere emprestar zero à emprestar qualquer outra quantia em caso de calote e portanto não existem calotes.

Vamos considerar agora os efeitos de um aumento de $k$. Conforme argumentaremos a medida que $k$ aumenta então, dado uma decisão passada de pagamento, aumenta também o volume crédito, $\left(b_{i} R_{t}\right)$. Considere que $\left(b_{i} R_{t}\right)$ seja tal que para $k=k^{\prime}$ a seguinte restrição judicial valha com igualdade:

$$
\begin{gathered}
E\left[h_{j, t+1}\left(d_{t+1}=1 \mid d_{t}\right)+\beta V\left(d_{t+2}, b_{i_{t+1}} \mid d_{t+1}=1\right)\right]= \\
\mathrm{E}\left[\mathrm{h}_{j, t+1}\left(d_{t+1}=0 \mid d_{t}\right)+\beta V\left(d_{t+2}, b_{i_{t+1}} \mid d_{t+1}=0\right)\right]
\end{gathered}
$$

Tome $k^{\prime \prime}>k^{\prime}$ então teremos que a restrição judicial vale com a seguinte desigualdade:

$$
\begin{gathered}
E\left[h_{j, t+1}\left(d_{t+1}=1 \mid d_{t}\right)+\beta V\left(d_{t+2}, b_{i_{t+1}} \mid d_{t+1}=1\right)\right]> \\
\mathrm{E}\left[\mathrm{h}_{j, t+1}\left(d_{t+1}=0 \mid d_{t}\right)+\beta V\left(d_{t+2}, b_{i_{t+1}} \mid d_{t+1}=0\right)\right]
\end{gathered}
$$

Note que para restrição acima valer com igualdade devemos ter $\left(b_{o} R_{t}\right)^{\prime}>\left(b_{o} R_{t}\right)$ isso por que o lado esquerdo da desiqualdade é decrescente em $\left(b_{o} R_{t}\right)$. Para ver isso note que:

$$
h_{j, t}\left(d_{t} \mid d_{t-1}\right)=E\left[\sum_{o} \alpha_{o} u\left(c_{o, t}\right)+\sum_{i} \alpha_{i} u\left(c_{i, t}\right)\right]-k\left(d_{t}-d_{t-1}\right)^{2}
$$

Sendo $d_{t-1}=1$ então: 


$$
\begin{gathered}
h_{j, t}\left(d_{t}=1 \mid d_{t-1}\right)=E\left[\sum_{o} \alpha_{o} u\left(c_{o, t}\right)+\sum_{i} \alpha_{i} u\left(c_{i, t}\right)\right] \\
h_{j, t}\left(d_{t}=0 \mid d_{t-1}\right)=E\left[\sum_{o} \alpha_{o} u\left(c_{o, t}\right)+\sum_{i} \alpha_{i} u\left(c_{i, t}\right)\right]-k
\end{gathered}
$$

Note que $\sum_{i} \alpha_{i} u\left(c_{i, t}\right)$ independe de $\left(b_{o} R_{t}\right)$ e o termo $E\left[\sum_{o} \alpha_{o} u\left(c_{o, t}\right)\right]$ é decrescente em $\left(b_{o} R_{t}\right)$ uma vez que:

$$
E\left[\sum_{o} \alpha_{o} u\left(c_{o, t}\right)\right]=E\left[\sum_{o} \alpha_{o} u\left(W_{o, t}+b_{o} R_{t}\right)\right]
$$

Note que para qualquer $b_{o}>0$ o equilíbrio no mercado de crédito requer que $\sum_{o} \alpha_{o} b_{o}=0$. Então conforme argumentamos um aumento de $k$ relaxa a restrição judiciária e possibilita um aumento do volume de crédito.

\section{2..8 Jurisprudência e a Taxa de Juros}

Como vimos acima a medida que $k$ aumenta, o volume de crédito, $\left(b_{i} R_{t}\right)$, também aumenta para o caso em que $d_{t-1}=1$. Vamos analisar agora como $R_{t}$ isoladamente responde ao aumento de $k$. Conforme vimos ao resolver o modelo o agente de renda alta escolhe $b_{i}$ afim de satisfazer a seguinte condição de primeira ordem:

$$
u^{\prime}\left(c_{i, t}\right)=\beta E\left[u^{\prime}\left(c_{i, t+1}\right)\right] R_{t}
$$

Que pode ser reescrita da seguinte forma:

$$
u^{\prime}\left(W_{H}-b_{i}\right)=\left[\alpha u^{\prime}\left(W_{H}+b_{i} R_{t}\right)+(1-\alpha) u^{\prime}\left(W_{L}+b_{i} R_{t}\right)\right] R_{t} \beta
$$

Considere que para $R_{t}=R$ a condição de primeira ordem valha com igualdade para $b_{i}=b$, ou seja, tenhamos o seguinte:

$$
u^{\prime}\left(W_{H}-b\right)=\alpha u^{\prime}\left(W_{H}+b R\right)+(1-\alpha) u^{\prime}\left(W_{L}+b R\right) R \beta
$$


Agora tome $R^{\prime}>R$. neste caso o lado direito da igualdade passa a ser maior que o lado esquerdo, ou seja, para $R^{\prime}>R$ temos:

$$
u^{\prime}\left(W_{H}-b\right)<\alpha u^{\prime}\left(W_{H}+b R^{\prime}\right)+(1-\alpha) u^{\prime}\left(W_{L}+b R^{\prime}\right) R^{\prime} \beta
$$

Sendo $u($.$) estritamente côncava devemos ter que u^{\prime}($.$) é decrescente em seu argumento.$ Desta forma para que a restrição volte a valer com igualde devemos ter $b^{\prime}>b$. Sendo assim o agente de renda alta oferta mais crédito somente para uma taxa de juros maior. Sendo assim se $\left(b_{i} R_{t}\right)$ aumenta, entõ devemos ter necessariamente que $R_{t}$ aumenta. desta forma a taxa de juros de equilíbrio depende positivamente do custo da jurisprudência, $k$.

\section{2..9 Resultados Numéricos}

A seguir serão apresentados alguns resultados numéricos para os modelos propostos. Estaremos resolvendo para o caso em que metade dos agentes recebe renda alta e a outra metade renda baixa, ou seja, $\alpha_{H}=\alpha_{L}=0.5$. Além disso, estamos considerando o caso em que a função de utilidade do agente é do tipo logarítmica, ou seja, $u()=.\ln ($.$) . Adi-$ cionalmente temos $W_{H}=4, W_{L}=2$ e $\beta=0.65$. O modelo foi resolvido no Matlab de acordo com os passos apresentados nas páginas anteriores.

Ao resolver o modelo observamos que o nível de empréstimos tolerado pelo juiz, $b_{J, t+1}$, depende positivamente do custo da jurispridência para o caso em que o juiz herda uma decisão passada onde foi ordenado o pagamento, ou seja, quando $d_{t-1}=1$ quanto maior $k$ maior será o nível de empréstimos que deixará o juiz indiferente entre calote ou pagamento para uma dada taxa de juros.

Como podemos ver na figura 4, quando o custo da jurisprudência é menor que um determinado valor, inexiste mercado de empréstimos para os jovens de baixa renda. A partir de um determinado valor de $k$ o mercado de empréstimos passa a existir e para um $k$ maior o mercado atinge a situação ótima, ou seja, $b_{L}^{*}=b^{*}$. Abaixo serão apresentados os 
gráficos para o nível de empréstimos de equilíbrio em função do custo da jurisprudência, para a taxa de juros de equilíbrio e para o o excedente social esperado.

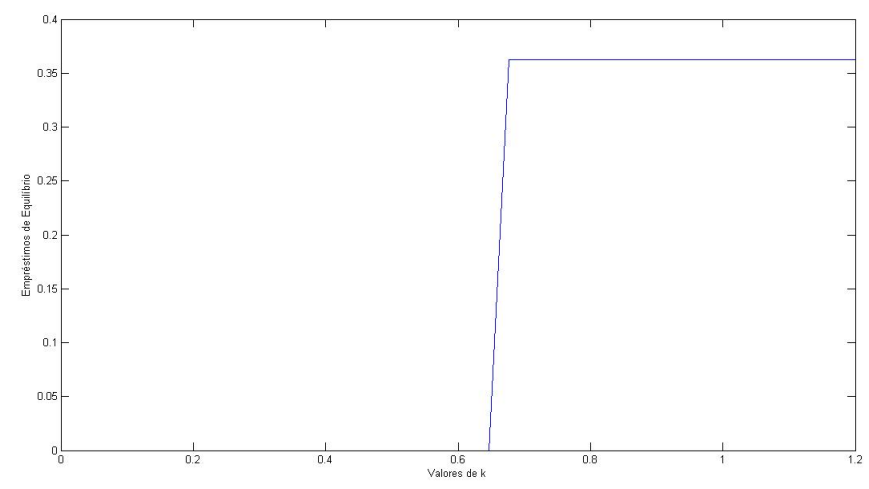

Figure 4: Montante de empréstimos de equilíbrio como função do custo da jurisprudência

Como podemos observar na figura 4, o montante de empréstimos de equilíbrio depende positivamente do custo que o juiz tem ao tomar uma decisão diferente da anterior. Podemos observar ainda que dependendo do valor de $k$ o mercado de empréstimos inexiste, mesmo que o juiz herde uma decisão de pagamento. Por outro lado podemos notar que a medida que o custo aumenta, o montante de empréstimos caminha para o que seria o nível ótimo para o caso em que os agentes não estão restritos.

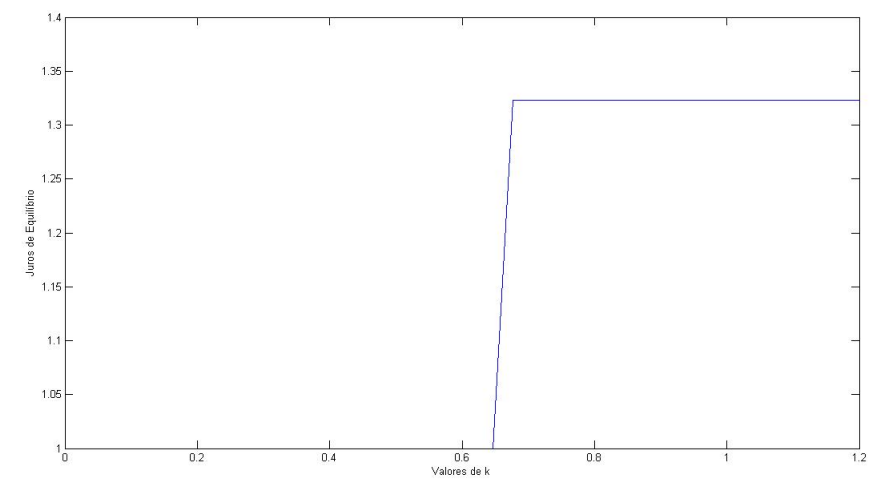

Figure 5: Taxa de juros de equilíbrio como função do custo da jurisprudência

Como podemos observar na figura 5 o mesmo acontece com a taxa de juros de equilíbrio da economia.

Na figura 6 podemos observar o excedente social esperado como função do custo da jurisprudência. Note que o excedente social esperado aumenta quando $k$ é tal que o mercado 


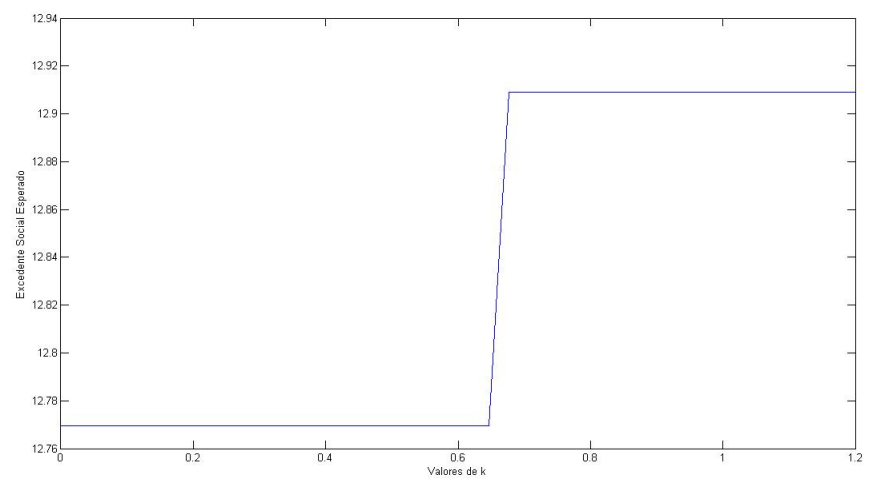

Figure 6: Excedente social esperado como função do custo da jurisprudência de empréstimos passa a existir e apartir de então fica constantemente mais elevado. 


\section{3. Ênfase do Sistema Legal: Jurisprudência e Recomendação}

\section{Legal}

A seguir flexibilizaremos o valor de $\gamma$ que antes estava fixado como sendo igual à unidade.

Desta forma a forma funcional da utilidade do juiz é dada por:

$$
H_{j}\left(d_{t} \mid d_{t-1}\right)=\sum_{t=t_{0}}^{T} \beta^{t-t_{0}} E\left[\sum_{o} \alpha_{o} u\left(c_{o, t}\left(d_{t}\right)\right)+\sum_{i} \alpha_{i} u\left(c_{i, t}\left(d_{t}\right)\right)\right]-K
$$

Em que:

$$
K=k\left(d^{*}-d_{t}\right)^{2}(1-\gamma)+k\left(d_{t}-d_{t-1}\right)^{2} \gamma
$$

Os passos para resolução do modelo são análogos aos que foram feitos na seção 2.

\section{3..1 Resultados Numéricos}

Nesta seção a variável de interesse é o parâmetro $\gamma$. Como vimos, quando temos $\gamma=1$ significa que estamo em um sistema legal onde as decisões são tomadas baseadas unicamente no critério de jurisprudência. Por outro lado, quando $\gamma=0$ estamos em um sistema legal onde as decisões são tomadas unicamente seguindo uma recomendação, um código. Primeiramente vamos apresentar os resultados para o montande de empréstimos de equilíbrio em função de $\gamma$. A seguir nas figuras 7 e 8 podemos ver, respectivamente, a taxa de juros de equilíbrio e o montande de empréstimos de equilíbrio.

A seguir focaremos nos resultados para os dois parâmetros de interesse, ou seja, $\gamma$ e $k$. Primeiro apresentaremos, na figura 9, como o volume de crédito se comporta em relação a $\gamma$ e $k$

Como podemos observar na figura 9 quanto maior a importância da jurisprudência na tomada de decisão do judiciário, maior será o volume de crédito tolerado pelo judiciário 


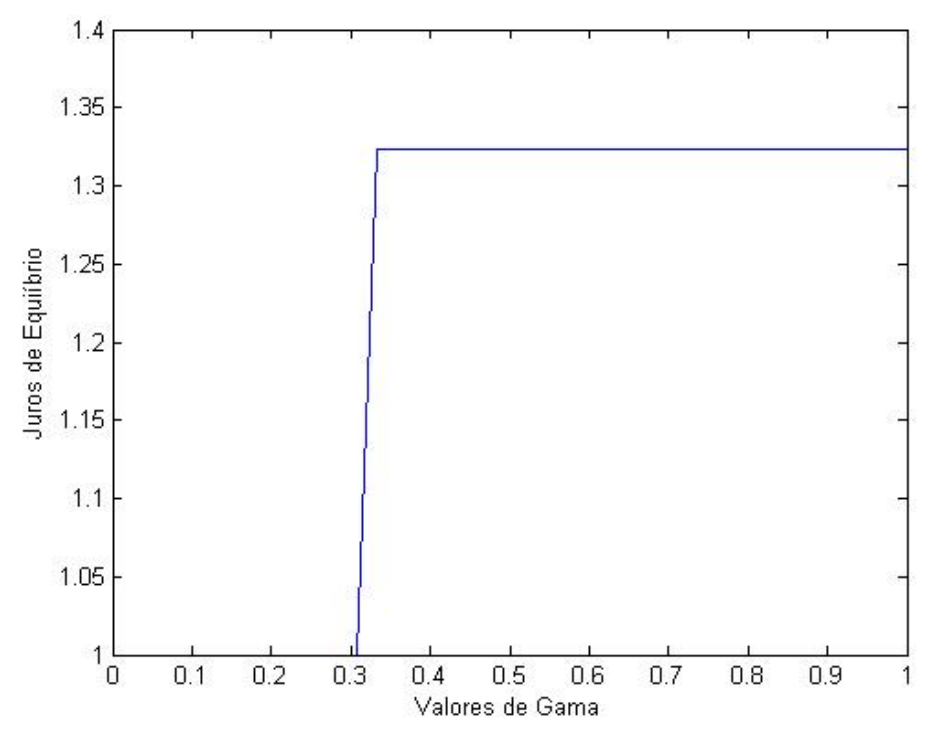

Figure 7: Taxa de juros de equilíbrio como função de $\gamma$.

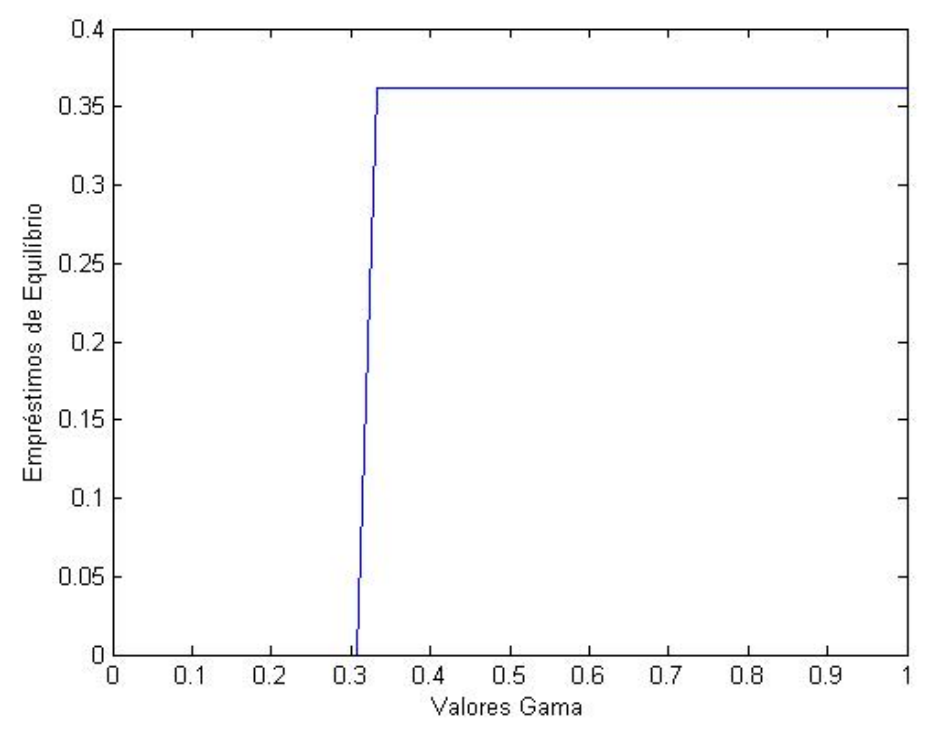

Figure 8: Empréstimos de equilíbrio como função de $\gamma$.

na economia. Na figura 10 e 11 a seguir apresentaremos respectivamente o montante de crédito e os juros de equilíbrio como função de $k$ e $\gamma$.

Como podemos observar nas figuras 10 e 11 o mercado de empréstimos inexiste para valores baixos de $k$ e $\gamma$ em uma economia fechada. Para estes casos em que inexiste o mercado a taxa de juros foi definida como sendo igual a unidade e os empréstimos estão zerados como podemos observar. 


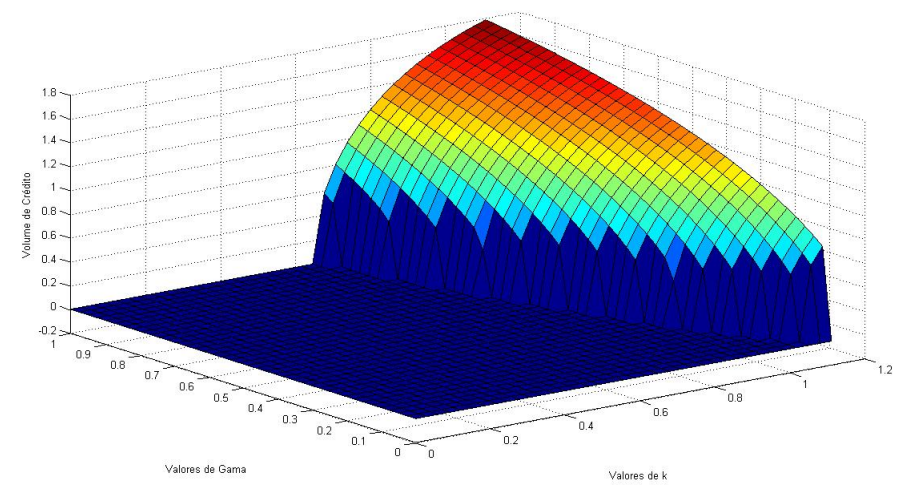

Figure 9: Volume de crédito como função do custo da jurisprudência e de $\gamma$.

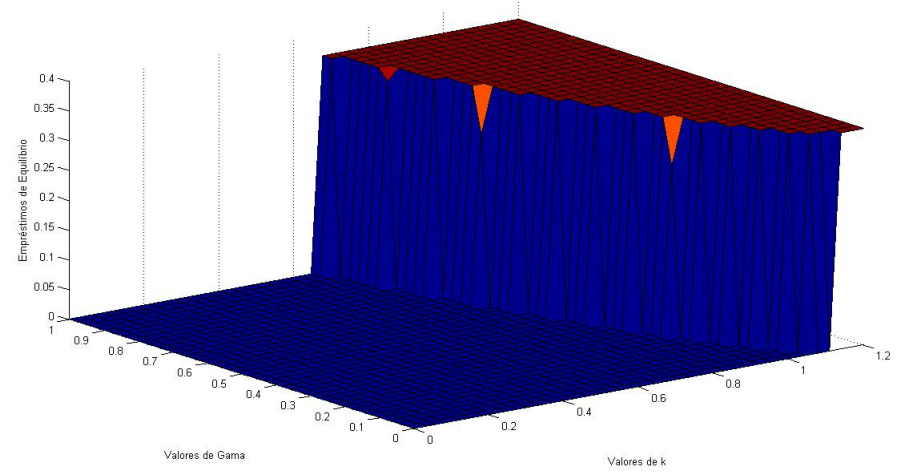

Figure 10: Empréstimos de Equilíbrio como função do custo da jurisprudência e de $\gamma$.

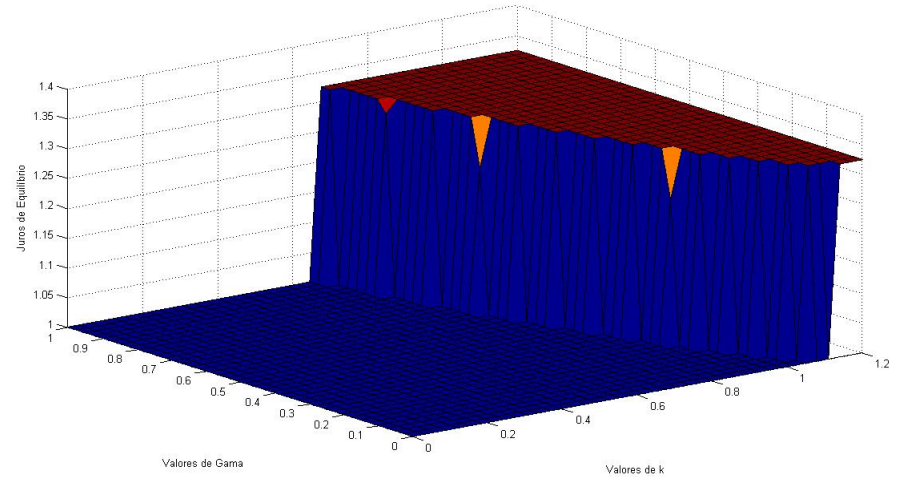

Figure 11: Juros de Equilíbrio como função do custo da jurisprudência e de $\gamma$. 


\section{Considerações Finais}

Após La Porta, Lopez-de-Silanes, Shleifer e Vishny a origem legal de um país ganhou atenção na literatura. De acordo com a Teoria da Origem Legal diferentes graus de desenvolvimento financeiro podem ser explicados através de diferentes origens. Basicamente a literatura divide a origem legal de um país em dois grupos. Um daqueles que têm suas leis baseadas na tradição britânica da Lei Comum e um outro grupo, daqueles que seguiram a tradição da Lei Civil. Essencialmente podemos ver a jurisprudência como um dos principais fatores que diferencia essas duas tradições. A literatura empírica comprova que de fato países com um sistema legal baseado na lei comum apresentam um maior desenvolvimento financeiro. Neste trabalho buscamos propor um modelo para analisar os efeitos da interferência judicial no mercado de crédito. Na ausência de jurisprudência a interferência judicial impossibilita que empréstimos sejam feitos entre os agentes de renda alta e baixa. Na presença de jurisprudência encontramos que quanto maior o custo de desviar da decisão passada maior o volume de crédito ofertado na economia para o caso em que o juiz herda uma decisão passada na qual foi determinado o pagamento dos empréstimos. Além disso, vimos que em equilíbrio não existem calotes. Um outro resultado interessante foi que o aumento do custo da jurisprudência aumenta a taxa de juros. Ao flexibilizar o valor de $\gamma$ no modelo pudemos observar que quanto maior a importância da jurisprudência na tomada de decisão do judiciário, maior será o volume de crédito na economia. Desta forma a jurisprudência seria o meio pelo qual um sistema legal baseado na lei comum possibilitaria um maior desenvolvimento financeiro que países com sistema legal baseado na lei civil. 


\section{Referências Bibliográficas}

Beck, T., Demirgüç-Kunt, A., and Levine, R. (2003a). Law and finance. why does legal origin matter? Journal of Comparative Economics, (1):265-296.

Beck, T., Demirgüç-Kunt, A., and Levine, R. (2003b). Legal obstacles to external finance. ver, 7(1):265-296.

Beck, T., Kunt, A. D., and Levine, R. (2003c). Law, endowments, and finance. Journal of Financial Economics, 2(1):1980-2022.

Bernhardt, H. L. . D. (2000). Enterprise, inequality and economic development. Review of Economic Studies, (1):147-168.

Gennaioli, N. (2006). Optimal contracts with enforcement risk. ver, ver(ver):1455-1508.

Goldsmith, R. (1969). Mixed jurisdictions: common law v. civil law (codified and uncodified. Louisiana Law Review, (3):60.

Jovanovic, D. E. . B. (1989). An estimated model of entrepreneurial choice under liquidity constraints. Journal of Political Economy, (4):808-827.

Leth-Petrsen, S. (2010). Intertemporal consumption and credit constraints: Does total expenditure respond to an exogenous shock to credit? American Economic Review, (3):80-110.

Newman, A. V. B. . A. F. (1993). Occupational choice and the process of development. Journal of Political Economy, (2):274-298.

Porta, R. L., de Silanes, F. L., Shleifer, A., and Vishny, R. (1997). Legal determinants of external finance. Journal of Finance, (1131-1150):1.

Porta, R. L., de Silanes, F. L., Shleifer, A., and Vishny, R. (1998). Law and finance. Journa of Political Economy, (1):1113-1150.

Porta, R. L., de Silanes, F. L., Shleifer, A., and Vishny, R. (1999). Investor protection and corporate valuation. NBER, (7403):1-50.

Porta, R. L., de Silanes, F. L., Shleifer, A., and Vishny, R. (2000). Investor protection and corporate governance. Journal of Financial Economics, (58):3-28.

Riboni, A. (2006). Courts' decision making withoutcommitment: a comparative analysis. American Law Economics, (xx):xx.

Tetley, W. (2000). Mixed jurisdictions: common law v. civil law (codified and uncodified. Louisiana Law Review, (3):60.

Ueda, R. T. . K. (2010). Welfare gains from fnancial liberalization. International Economic Review, (3):60.

Vojislav, A. D.-K. . M. (1998). Law, finance, and firm growth. Journal of Finance, (53):2107-2139. 
Weiss, J. S. . A. (1981). Credit rationing in markets with imperfect information. American Economic Review, (3):393-410.

Zingales, R. R. . L. (2003). The great reversals: the politics of financial development in the twentieth century. Journal of Financial Economics, (69):5-50. 